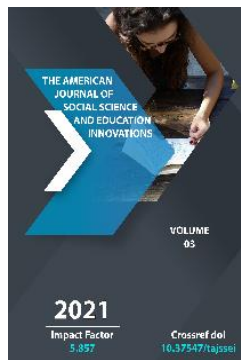

\title{
Methods Of Orthographic And Grammatic Analysis Of Uzbek Writing
}

\author{
Abduraxmonova Umida Rustamovna \\ Teacher Of The Department Of Information Technologies Of Tashkent State University Of \\ Uzbek Language And Literature Named After Alisher Navoi, Uzbekistan
}

\begin{abstract}
Journal Website: http://usajournalshub.c om/index,php/tajssei

Copyright: Original content from this work may be used under the terms of the creative commons attributes 4.0 licence.
\end{abstract}

\section{ABSTRACT}

Orthography is a system of rules adopted to correctly express an idea through writing, which ensures that the idea is equally expressed both for the writer and for the reader. In the teaching of orthography, hearing and sight play an important role. In addition, factors such as logical thinking, memory, intelligence also play an important role in the formation of orthographic skills in students. These are those in which orthography creates a certain system in teaching, one complements the other. This article will give an idea of the methods of orthographic analysis.

\section{KEYWORDS}

Orthography, phonetic principle, historical-traditional principle, differential principle, grammatical lexical analysis.

\section{INTRODUCTION}

Orthography Greek means to write correctly. The sum of the rules for writing the word ezakbases and suffixes in a single way is called orthogra-fiya. Orthography is characteristic of the written form of the literary language.
Orthography, in turn, is inextricably linked with orhepia and the alphabet (graphics). But in Uzbek orthography there are still minor shortcomings and some confusion. The reason for this: 1) omissions in the Uzbek Alphabet: 2) 
orepepia-the case; 3 ) the spelling of compound words is empty-handed.

\section{Principles of Uzbek orthography}

Principle (principle) - means a Latin beginning. Spelling principles are the foundation of writing. There are three basic principles of orthography: 1) phonetic Principle; 2) morphological Principle; 3) historicaltraditional principle. In addition to these, there are also 4) differential principles and 5) graphical or etymological principles. But the next Iqbal does not play a key role. These principles in Uzbek orthography work in interdependence. These are strictly adhered to in order to avoid diversity in writing.

\section{Phonetic principle}

The spelling of speech sounds in the composition of the word according to the pronunciation and hearing is characteristic of the phonetic principle. According to this, the words are written in the literary pronunciation in the same way as they are pronounced. For example, the word La affiksi from the core of consciousness is written not in the form of consciousness, but in the form of an angla, that is, when pronouncing a Instead of o in the core, it is written in the same way. In the word transitive, which is formed from the basis of the case, instead of a is written o. (in the words tara-comb, too, so). Hence-Dec, Russian schyot, schyotka is also written in the style of a stick, brush, according to which the words are heard. The phonetic principle brings orthography closer to live pronunciation. In writing and pronunciation, to some extent, commonality is preserved. In our speech, the toasted Sou is pronounced in the style of the fallen Sou is pronounced. Sometimes at the end of the word one vowel is lowered and said (Like a consonant, a persen, a rust), these words are written differently or completely apart from the pronunciation. This circumstance indicates that the phonetic principle can not be the only principle of orthography. Just as well, because of the shortcomings in the alphabet, vowels are written in the same way, regardless of their hard and soft pronunciation: We, knee, girl, winter, lake, eye, sheep, lamb, soul, mother, wolf, round, like, Die, ur.

\section{Morphological principle}

The so-called morphological principle of writing is called, not according to how the words and consonants in the speech are pronounced, but on the basis of their completeness or the choice of one of the options. The morphological principle promotes the storage and writing of words and morphemes in fixed forms in the literary language, ensures uniformity in writing.

For example, three suds, originating Su is said in the style. But they are written that according to the original three, come. Or it is written in the form, according to its completeness, despite the fact that is pronounced in the form of-la,- lor, - nar. The infinitive form of the verbmoq, as well as almost all forms of suffixes, is written on the morphological principle: possessive suffixes: -im,- ing,- i, consonant affixes: -of,- ni,- da (except for the declension agreement), the word conjugators are also written with the same morphological form preserved in the spelling, regardless of the variety of pronouns. Apparently, the morphological principle is considered to be the leading principle of Uzbek orthography.

\section{Historical-traditional principle}

The so-called historical-traditional principle of writing words in a form that does not 
correspond to the norm of pronunciation at the moment, has become obsolete. In other words, words are written not according to the current state of things, but according to a rule that has become a tradition: like Tsarist Russia, contractor, Bill, mercy.

In the current orthography, some forms of writing on the basis of the historical-traditional principle are as follows::

1. According to the tradition (poetry talabi), which is used in our classical literature in the form of-clay,- clay: borgil // borgil.

Wait for me and I will return (K.Simon)

So enough instrumental, so do your tune,

So do not hit my chest enough dagger (A.Oripov).

2. The meaning of the meaning of the goalThe Shape of the gani-gali, -Gali, -kali, -Qali forms:

Come to see me,

Watch did you come to sing (song).

3. Present-future-present form of adjective forming-ur form:

I will withstand the star grass

Tolerating phases inspection (A.Aripov)

4. Mo shape:

Is love all over

Toshu with scales (E.Unit)

Black eyebrow moon is not a crescent on your face (P.Mo ' min)

5. Such words as Navoi, Fidoi, ATOI entered our orthography on the basis of mastering the rule of the Arabic language.

\section{Differential principle}

The principle of differentiation (differentiation) is called when words that do not clearly differ from each other in pronunciation or come to a level where their mutual differences are almost imperceptible are separated by a special rule in writing. This principle is poorly applied. Some examples:

1. Close, formative words differ in writing with the help of a gloomy sign: like a claim - cure, Nasha - nasha, poetry - lion, pace photo, persecution - wear.

2. Some formative words differ in pronunciation with the help of accents. In the spelling, an accent sign is placed on such words: atlas (card) - atlas (cloth), banda (Sheika) - banda (slave), compound (mixture)-compound (not included).

3. the suffixes-li and-Li were used differently in writing until 1956 year. Since 1956 year in our literary orthography began to use them differently. When expressing the meaning of belonging: urban, rural, Tashkent; in the sense of having-liiksi began to be used: equestrian, full-fledged. As a result of this, uniformity in spelling was achieved. Regardless, there are still cases of the use of these tokens without a difference. Compare: a bucket person is a bucket person and $b$.

4. -with, too, the words are different: connected - related, connected something that connects a mole or hay; emptiness - wash, emptiness - like space.

\section{Etymological or graphic principle}

Writing on the basis of the preservation of the ancient etymological or graphical state of the mastered words is called an etymological or graphical principle in spelling. In other words, assimilation in writing is maintained by the 
etymology of the word. For example, such words as Navoi, Lutfi, and problem are also written on the same principle. The Russian language and the role mastered by it, such words as quintal, tender, computer, bank, senator, action are written on the principle of graph. It is also characteristic that some Russian-International words, which are difficult for the pronunciation of the Uzbek language, are written and pronounced according to the current orthographic rules, in an exceptional way, in accordance with the pronunciation characteristics of our language: kiosk-kiosk, bank - Bank.

At the same time, there is also an inseparable connection between the principles of orthography. At the end of such words as family, Navoi, the suffix-VI,- iy corresponds both to the historical-traditional principle and to the etymological-graphic principle. Phonetic and morphological principles in the writing of the dative case form-ga, -ka, -qa are suitable.

Spelling is a special speech qualification. Correct writing is a special quot; speech activity; the writing is also a complex action, on the basis of which the speech lies. Spelling qualification as a component of speech activity includes the correct syntactic structure of the sentence, the exact application of the word stylistically. The spelling qualification is a complex qualification, it is created in the process of long-standing exercises and is based on the ability to analyze the word from the phonetic side, determine its morphemic composition, etc. Psychology defines skill as automatic movement, that is, a conscious movement that is gradually automated as a result of exercise. Automation depends on the ease or difficulty of the learned spelling rule. Spelling skills are not considered automatic by their nature. The skill set on the basis of the qualification is strengthened, improved, improved (the action accelerates, begins to be clear and correct, is fulfilled reliably and sparingly); therefore, the structure of the activity is reconstructed: work with a small unit goes to work with a wider, whole, additional units (for example, with the transfer of the word in letters, with the transfer of syllables, then with the transfer of the word in a holistic way, and then with the transfer of the sentence). One orthographic qualification automates, another phenomenon related to spelling is studied, and gradually the skill of writing the word correctly is formed. In general, writing remains a conscious process as a complex action. For the formation of an orthographic qualification, thinking activity is required from the reader. To master a correct writing phenomenon, it is practiced not only to study and remember, but also to analyze and synthesize. It is important to use the method of comparison to determine the similar and different sides of the grammatical and syntactic phenomena, as well as to divide the word and word forms into certain grammatical or graphic groups, to put into a particular system, the use of explanatory and proof exercises.

The methodology for working on the formation of spelling skills in primary school students is determined by the psychological nature of the teacher's spelling skills. Opening the essence of the rule rule the rule means to explain which part of the speech the word belongs to, which category of speech it is or manages to write a grammatical form, in which case the signs are the leaders. When choosing a material to introduce students to the rule, the teacher will definitely take into account these leading signs. On the rules are treated according to the textbook. In this it is 
important that the students understand the structure of the rule. Therefore, the rule in the textbook is divided into parts. This task is performed by students in the process of working with exercises. Students apply it to their writing experience by giving an example of the learned rule and doing a variety of exercises. The methodology for working on the rule is chosen depending on the basis of this rule.

It will be convenient to master it if the students perform tasks that will help to distinguish the main idea in the rule. Because children work with a certain material and, when analyzing it, allocate a significant part of the rule, consciously assimilate the rule. Something, for example, comparing the pronunciation and writing of vowels, word categories, parts of speech to each other increases the mental activity of students. It is also important to clearly write down the separated sign of the rule again in the Bunda. The teacher's questions will help to distinguish an important thought, which is reflected in the rule. These questions, in turn, are also considered a plan to formulate the rule. In addition to working as a team on the rule, it is also possible to apply an independent method of work using the textbook. In mastering the new rule is based on the knowledge learned. To do this, the new rule is tied to the rules that were previously studied. In this case, the injection or comparison method is used and the similar sides are determined. It is important for readers to form a clear picture of the rule, accordingly, the rule should not be dry memorization, but the features in the correct writing of the word should be clearly explained in the example of the material.

As soon as the skills go to strengthening, some of its sides begin to become accustomed, that is, the reader will continue to write the words correctly, without remembering or thinking about the rules of their spelling. With the conscious assimilation of spelling, writing begins to become a skill. Undoubtedly, such mental activity plays a decisive role. Orthography teaching depends on the teacher's ability to choose the most diverse methods of performance, appropriate use of all writing exercises, efficient and correct use of modern methods and information technologies in the organization of any spelling lesson, taking into account the psychological side of the students, memory, attention, perception, ability to understand, age, individual characteristics and other circumstances. Accordingly, when choosing techniques, it is recommended to take into account the following situations::

The knowledge that the method and the exercise are given - should correspond to the material;

The knowledge that students are given is the willingness to accept the material, for example, to switch to a new topic in mathematics, the reader must know the previously mentioned rules;

The text chosen for the written work should be in demand, both in terms of content and in terms of richness of the passed orthogram;

Orthography is a method of teaching or exercises that must ensure conscious mastering of spelling;

Exercise should be consistent with the independent performance qualification of students;

Orthography is the method of teaching and ensuring that the exercises are consistent; for 
example, before the control dictator should be transplanted writing, educational dictator, creative work should be conducted. It is not recommended to switch to a new type of exercise until the students master the technique of execution of the given task;

Oral exercises should also be performed before writing exercises;

All methods of teaching orthography should form one common system.

When teaching how to write correctly, it is necessary to achieve the proportionality of oral exercises with written exercises. To teach spelling, writing correctly, the size of the selected texts must also correspond to each class. Orthographic exercises include the following, and the spelling qualification is aimed at ensuring the automation of conscious speech activity:

Matikmatik-orthographic analysis;

Download writing;

Dictators;

Lexical-grammatic analysis;

Descriptions.

Matik in orthographic-orthographic and lexicalorthographic analysis, the connection of orthography with grammaticism and lexis, the factors that determine the activity of students in transcribing and dictation, in particular, vision and hand movement in transcribing, hearing in dictation are taken into account.

\section{REFERENCES}

1. Acxiom Corporation (2011). Experiences verifying the identity of online students. Acxiom Corporation. Al-Alone, K. I. (2015). Learning Effects of Using Learning Management System (Moodle) by Students of Arab Open University. Pp.15-40.

2. Proceedings of MAC-ETel 2015. Multidisciplinary Academic Conference on Education, Teaching and E-Learning, Prague. Al-Amleh, M. (2014). Identifying the Palestinian Culture According To Hofstede's Theory. MA thesis, Jerusalem, occupied Palestinian Territories: Al-Quds University. Alkailani, M., Azzam, I. A., \& Athamneh, A. B. (2012). Replicating Hofstede in Jordan: ungeneralized, reevaluating the Jordanian culture. International Business Research, 5 (4), p.71.

3. American University in Cairo News (2015) Faculty Reform Requires Change in the Mindset of Educators, Youth [Online], Cairo. Available at: http://www.aucegypt.edu/news/storie s/faculty-reform-requireschangemindset-educators-youth (Accessed 27/11/2017) Assad, R., Salehi-Isfahani, D., \& Hendy, R. (2014). Inequality of opportunity in educational attainment in Middle East and North Africa: evidence from household surveys. In Economic Research Forum Working Paper Series No (Vol. 834) 